Federal Reserve Bank of Dallas

Globalization and Monetary Policy Institute

Working Paper No. 111

http://www.dallasfed.org/assets/documents/institute/wpapers/2012/0111.pdf

\title{
The Perils of Aggregating Foreign Variables in Panel Data Models*
}

\author{
Michele Ca' Zorzi \\ European Central Bank \\ Alexander Chudik \\ Federal Reserve Bank of Dallas \\ Alistair Dieppe \\ European Central Bank
}

March 2012

\begin{abstract}
The curse of dimensionality refers to the difficulty of including all relevant variables in empirical applications due to the lack of sufficient degrees of freedom. A common solution to alleviate the problem in the context of open economy models is to aggregate foreign variables by constructing trade-weighted cross-sectional averages. This paper provides two key contributions in the context of static panel data models. The first is to show under what conditions the aggregation of foreign variables (AFV) leads to consistent estimates (as the time dimension $\mathrm{T}$ is fixed and the cross section dimension $\mathrm{N} \rightarrow \infty$ ). The second is to design a formal test to assess the admissibility of the AFV restriction and to evaluate the small sample properties of the test by undertaking Monte Carlo experiments. Finally, we illustrate an application in the context of the current account empirical literature where the AFV restriction is rejected.
\end{abstract}

JEL codes: C12, C31, C33, F41

\footnotetext{
* Michele Ca' Zorzi, European Central Bank, Kaiserstrasse 29, 60311, Frankfurt am Main, Germany. +49-1344-6563. michele.cazorzi@ecb.int. Alexander Chudik, Federal Reserve Bank of Dallas, 2200 N. Pearl Street, Dallas, TX 75201. 214-922-5769. alexander.chudik@dal.frb.org. Alistair Dieppe, European Central Bank, Kaiserstrasse 29, 60311, Frankfurt am Main, Germany. +49-1344-7888. alistair.dieppe@ecb.int. We have benfited from valuable comments by M. Hashem Pesaran, Shang-Jin Wei, G. Amisano, an anonymous referee and participants of the 2010 International Symposium on Econometrics of Specification Tests. The views in this paper are those of the authors and do not necessarily reflect the views of the European Central Bank, the Federal Reserve Bank of Dallas or the Federal Reserve System.
} 


\section{Introduction}

In open economy empirical applications often one cannot estimate the influences of all potentially relevant variables. This is known in the literature as the "curse of dimensionality". Over the years a number of approaches have been developed to overcome the dimensionality problem. For example, factor models explore the co-movement among variables to shrink the data. 1 Bayesian estimations, on the other hand, reduce the parameter space through the imposition of priors, see for instance Del Negro and Schorfheide (2004). Another approach which was introduced by Chudik and Pesaran (2011) is to apply restrictions on the coefficients which only become binding when the number of endogenous variables tends to infinity.

The solution which is commonly applied in the open economy macroeconomic literature, however, is generally simpler: i.e. to aggregate the number of foreign variables in the dataset by constructing cross sectional averages, typically using trade weights or financial or GDP weights. This way of proceeding is common across major fields in the open economic literature, including the applications related to the Purchasing Power Parity (PPP) hypothesis, foreign trade, current account, equilibrium exchange rate models, and small open economy macroeconometric models.

This paper illustrates how this common practice may be not as innocuous as generally thought both from a theoretical and empirical perspective.

The paper is structured as follows. Section 2 establishes in the context of a static panel model the restrictive conditions under which the aggregation of foreign variables (AFV) provides consistent estimates when the time dimension $(T)$ is fixed and the cross-section dimension $(N)$ tends to $\infty$. Section 3 develops a formal test to evaluate the AFV restriction. It consists of estimating an auxiliary regression and applying an F-test. The additional set of regressors are formed by aggregating foreign variables using a set of weights that need to be granular (such as equal weights). We show that the F-test converges to a $\chi^{2}$-distribution.

Section 4 investigates the small sample performance of the test by means of Monte Carlo experiments. Section 5 provides a application taken from the empirical current account literature, where the AFV restriction is applied and fails, discussing the importance of this finding in the context of the G20 debate on external imbalances and the possible implications for the estimation of equilibrium exchange rates. The last section concludes. Appendix A presents proofs and Appendix B

\footnotetext{
${ }^{1}$ Dynamic factor models were introduced in economics by Geweke (1977) and Sargent and Sims (1977) and later generalised to allow for weak cross sectional dependence by Forni and Lippi (2001), Forni et al. (2000) and Forni et al. (2004).
} 
derives a simple illustrative multicountry model of current account derived from first principles.

A word on notation before proceeding: $\varrho(\boldsymbol{A})$ is spectral radius of matrix $\boldsymbol{A}$ and $\|\boldsymbol{A}\|=$ $\sqrt{\varrho\left(\boldsymbol{A A}^{\prime}\right)}$ denotes the spectral norm of $\boldsymbol{A}$. All vectors are column vectors denoted by bold small letters. Matrices are denoted by capital bold letters. $a_{s}=O\left(b_{s}\right)$ states the deterministic sequence $a_{s}$ is at most of order $b_{s} . x_{s}=O_{p}\left(y_{s}\right)$ states random variable $x_{s}$ is at most of order $y_{s}$ in probability, and $x_{s} \stackrel{q . m .}{\rightarrow} y_{s}$ states that $x_{s}$ converges to $y_{s}$ in quadratic mean.

\section{Theoretical considerations on the impact of the AFV restriction}

This section illustrates the perils associated with the AFV restrictions in a static panel framework. For exposition purposes we consider a simple current account model, where in each country the current account depends on real GDP per capita of all countries. A simple rational for this could be that high per capita income countries might provide external financing to low per capita income countries. In more formal terms, suppose there are $N$ countries in the world economy, indexed by $i \in\{1,2, \ldots, N\}$, and let us define $\kappa_{i t}$, as the ratio between the current account $C A_{i t}$ and GDP, $Y_{i t}$. In this simple model the current account positions $\kappa_{i t}$ of country $i$ at time $t$ is a function of $a_{i t}$

$$
\kappa_{i t} \approx a_{i t}-\sum_{j=1}^{N} \omega_{i j} a_{j t}
$$

where $a_{i t}=\ln \left(Y_{i t} / L_{i}\right)$ is the logarithm of real GDP per capita in PPP terms (a proxy for productivity), and the aggregation weights satisfy

$$
\sum_{j=1}^{N} \omega_{i j}=1 \text { and } \omega_{i i}=0 \text { for all } i
$$

For ease of exposition we illustrate the concepts in terms of a current account model for later. The framework is, however, general and applicable to many other open economy applications, where $\kappa_{i t}$ is the dependent variable and $a_{j t}$ the key fundamental in $N$ countries with $j \in\{1,2, \ldots, N\}$. As discussed later an extension to multiple fundamentals is straightforward.

Turning more specifically to current account models, in Appendix B we derive a special case of model (1) from first principles, where the aggregation weights $\left\{\omega_{i j}\right\}$ are a function of the size of each economy in terms of GDP, see equations (B.10)-B.11). More complex models could lead, however, to a different set of weights, e.g. the aggregation weights could depend also on trade and 
financial interlinkages and not just the size. Unless the structure of the model is fully specified the true aggregation weights are generally not known.

If the true aggregation weights $\left\{\omega_{i j}\right\}$ were known, one could estimate the following linear model

$$
\kappa_{i t}=\beta z_{i t}+\eta_{i t}
$$

where

$$
z_{i t}=a_{i t}-\sum_{j=1}^{N} \omega_{i j} a_{j t}
$$

and $\eta_{i t}$ is an independently and identically distributed (IID) error term. However, since the weights $\left\{\omega_{i j}\right\}$ are in general unknown, we shall refer to regression (3) as infeasible.

Let $x_{i t}=a_{i t}-\sum_{j=1}^{N} w_{i j} a_{j t}$ be a regressor constructed from the data, using the weighting scheme $\left\{w_{i j}\right\}$. The feasible regression is:

$$
\kappa_{i t}=\beta x_{i t}+\epsilon_{i t},
$$

where it follows that the error term

$$
\epsilon_{i t}=\beta\left(z_{i t}-x_{i t}\right)+\eta_{i t}=\beta \sum_{j=1}^{N}\left(w_{i j}-\omega_{i j}\right) a_{j t}+\eta_{i t}
$$

is in general correlated with the regressor $x_{i t}$, and therefore the (pooled) least squares (LS) estimate of $\beta$ in the feasible regression (5) is in general biased and inconsistent for finite $N($ as $T \rightarrow \infty)$. However, the inconsistency of $\beta$ does not necessarily hold when $N \rightarrow \infty$, which is the commonly used asymptotics in panel estimations. For future reference, denote the pooled LS estimate of $\beta$ in the feasible regression $(5)$ as $\widehat{\beta}$, which can be written as

$$
\widehat{\beta}=\left(\mathbf{x}^{\prime} \mathbf{x}\right)^{-1} \mathbf{x}^{\prime} \boldsymbol{\kappa}
$$

where $\mathbf{x}$ and $\boldsymbol{\kappa}$ are $N T \times 1$ dimensional vectors of stacked observations.

We consider four different cases to assess the consequences of the AFV restriction in this static panel framework. The extension of the analysis below to multiple regressors is straightforward. 


\subsection{Case 1: Weakly cross-sectionally dependent productivity $\left\{a_{i t}\right\}$ in a world without neighborhood effects}

Suppose that the true aggregation weights $\left\{\omega_{i j}\right\}$ satisfy the following granularity conditions, in addition to the normalization condition (2):

$$
\begin{aligned}
\left\|\boldsymbol{\omega}_{i}\right\| & =O\left(N^{-\frac{1}{2}}\right) \\
\frac{\omega_{i j}}{\left\|\boldsymbol{\omega}_{i}\right\|} & =O\left(N^{-\frac{1}{2}}\right) \text { for any } i, j,
\end{aligned}
$$

where $\boldsymbol{\omega}_{i}=\left(\omega_{i 1}, \ldots, \omega_{i N}\right)^{\prime}$ is the vector of weights specific to country $i$. In terms of the special case developed in Appendix B, letting the size of each country in terms of GDP be $O(1)$ implies $\omega_{i j}=O\left(N^{-1}\right)$ (uniformly in $i$ and $j$ ) and the conditions $(8)-(9)$ are satisfied. This means that each economy has a negligible impact on all other economies. We refer to this case as a world that has no neighborhood effects.

Note that assuming conditions (8)-(9) hold is a much more restrictive assumption than what is normally understood as the small open economy assumption in the literature, i.e. where a small open economy is thought to have a negligible impact on the rest of the world as a whole but could affect some of its neighbors significantly.

We also assume that productivity follows a stationary cross-sectionally weakly dependent process $2^{2}$ in particular that

$$
a_{i t}=\vartheta_{i t}
$$

where $\left\|\operatorname{Var}\left(\boldsymbol{\vartheta}_{t}\right)\right\|=\|\boldsymbol{\Sigma}\|=O(1)$ and $E\left(\boldsymbol{\vartheta}_{t}\right)=0$.

It follows that for any ad-hoc non-random or predetermined weights $\mathbf{w}_{i}$ satisfying granularity conditions (8)-(9),

$$
\left\|\operatorname{Var}\left(\mathbf{w}_{i}^{\prime} \mathbf{a}_{t}\right)\right\|=\left\|\mathbf{w}_{i}^{\prime} \mathbf{\Sigma} \mathbf{w}_{i}\right\| \leq\left\|\mathbf{w}_{i}\right\|^{2}\|\mathbf{\Sigma}\|=O\left(N^{-1}\right),
$$

\footnotetext{
${ }^{2}$ See Chudik, Pesaran, and Tosetti (2011) for a definition of weak and strong cross section dependence and Pesaran (2012) for the testing the null hypothesis of weak cross section dependence. See also Bailey et al. (2012) for a related discussion on the characterization of patterns of cross section dependence.
} 
and therefore

$$
\bar{a}_{w i t}=\sum_{j=1}^{N} w_{i j} a_{j t} \stackrel{q . m .}{\rightarrow} 0 .
$$

This implies

$$
z_{i t}-x_{i t} \stackrel{q . m .}{\rightarrow} 0, \eta_{i t}-\epsilon_{i t} \stackrel{q . m .}{\rightarrow} 0,
$$

and the regressions (3) and (5) are asymptotically (for large $N$ ) the same. Thus as $N \rightarrow \infty$ (and $T$ is fixed), the estimate of coefficient $\beta$ in the feasible regression (5) is consistent for any adhoc weights $\left\{w_{i j}\right\}$, even if different from $\left\{\omega_{i j}\right\}$ as long as they satisfy the granularity conditions. Constructing cross sectional averages leads in this case to consistent estimates even if the weights are not the "true" ones $3^{3}$ However, the required conditions are quite restrictive.

\subsection{Case 2: Strongly cross-sectionally dependent productivity $\left\{a_{i t}\right\}$ in a world without neighborhood effects}

Turning to the second case, we keep the restrictive assumption of a world without neighborhood effects but this time we allow productivity $\left\{a_{i t}\right\}$ to follow a strongly cross-sectionally dependent (CSD) process

$$
a_{i t}=\vartheta_{i t}+\gamma_{i} f_{t},
$$

where $f_{t}$ is unobserved productivity common factor and $\gamma_{i}$ is the corresponding factor loading, which is assumed to be $I I D$ with mean $\gamma \neq 0$ and a finite variance.

It follows that

$$
\epsilon_{i t}-\eta_{i t} \stackrel{q . m .}{\rightarrow}\left(\bar{\gamma}_{w i}-\bar{\gamma}_{\omega i}\right) f_{t} \stackrel{q . m .}{\rightarrow} 0
$$

where both $\bar{\gamma}_{w i}=\sum_{j=1}^{N} w_{i j} \gamma_{j} \stackrel{q . m .}{\rightarrow} \gamma$ and $\bar{\gamma}_{\omega i}=\sum_{j=1}^{N} \omega_{i j} \gamma_{j} \stackrel{q . m .}{\rightarrow} \gamma$, provided that both $\left\{w_{i j}\right\}$ and $\left\{\omega_{i j}\right\}$ satisfy conditions (2) and (8)-(9). Hence again, for large $N$, the infeasible regression (3) and the feasible regression (5) are asymptotically the same. This implies consistency of $\widehat{\beta}$ (in the feasible regression). However, if the factor loadings are not randomly distributed, but are deterministic $O(1)$ coefficients, then $\widehat{\beta}$ is consistent only when $E\left|\bar{\gamma}_{w i}-\bar{\gamma}_{\omega i}\right| \rightarrow 0$. In short summary, a world without neighborhood effects is not a sufficient condition to guarantee consistency of $\widehat{\beta}$.

\footnotetext{
${ }^{3}$ When both vectors $\mathbf{w}_{i}$ and $\boldsymbol{\omega}_{i}$ satisfy the granularity conditions, then the weights errors are bounded by $\left|w_{i j}-\omega_{i j}\right|<K / N$, for all $i, j$, where $K<\infty$ is a positive constant that does not depend on $N$.
} 


\subsection{Case 3: Weakly cross-sectionally dependent productivity $\left\{a_{i t}\right\}$ and a domi- nant economy}

The third case assumes that productivity $\left\{a_{i t}\right\}$ is cross sectionally weakly dependent (CWD), as in equation (10). However, it also considers that the world features a dominant economy. In particular, let us assume that the true weights $\left\{\omega_{i j}\right\}$ satisfy

$$
\omega_{i 1}=O(1), \text { for } i=2,3, \ldots, N
$$

and $\sum_{i=2}^{N} \omega_{i 1}$ is unbounded in $N$, while the vectors $\boldsymbol{\omega}_{i,-1}=\left(0, \omega_{i 2}, \ldots, \omega_{i N}\right)^{\prime}$ satisfy the granularity conditions, namely

$$
\left\|\boldsymbol{\omega}_{i,-1}\right\|=O\left(N^{-1 / 2}\right)
$$

and

$$
\frac{\omega_{i j}}{\left\|\boldsymbol{\omega}_{i,-1}\right\|}=O\left(N^{-1 / 2}\right) \text {, for any } i \text { and any } j>1 \text {. }
$$

An easily intuitive scenario for the presence of dominant effects is one in which one economy say $j=1$ is 'large' in the sense that the share of its output in the world economy is bounded away from zero.

Furthermore, suppose that the weights $\left\{w_{i j}\right\}$ used in the feasible regressions have the same order of magnitudes as the unknown weights $\left\{\omega_{i j}\right\}$, that is $w_{i 1}=O(1)$ and $\mathbf{w}_{i,-1}=\left(0, w_{i 2}, \ldots, w_{i N}\right)^{\prime}$ satisfy the granularity conditions. It follows that

$$
k_{i t}-x_{i t}-\delta_{i} a_{1 t}-\eta_{i t} \stackrel{q . m .}{\rightarrow} 0
$$

where $\delta_{i}=\left(\omega_{1}-w_{i 1}\right)=O(1)$ in general. The dominance of one economy, for example the United States, becomes a common factor for the remaining economies in the panel the errors in the feasible regression follow an unobserved common factor structure (in the limit as $N \rightarrow \infty$ ) and are correlated with regressor $x_{i t}$ :

$$
\epsilon_{i t} \stackrel{q . m .}{\rightarrow} \eta_{i t}+\delta_{i} a_{1 t}
$$

where $\delta_{i}$ is the corresponding factor loading. This implies inconsistency of $\widehat{\beta}$.

\footnotetext{
${ }^{4}$ See also Chudik and Pesaran (2012) for a related discussion in the context of a general infinite-dimensional VARs.
} 


\subsection{Case 4: Weakly cross-sectionally dependent productivity $\left\{a_{i t}\right\}$ in a world with neighborhood effects}

In the fourth case productivity $\left\{a_{i t}\right\}$ is again cross sectionally weakly dependent but this time we allow for neighborhood effects while assuming that no economy is dominant. Let $\mathcal{I}_{i} \subset\{1,2, \ldots, N\}$ denotes the bounded set of neighbors for the economy $i$,

$$
\omega_{i j}=O(1) \text { and bounded away from zero for } j \in \mathcal{I}_{i},
$$

and

$$
\omega_{i j}=O\left(N^{-1}\right) \text { for } j \notin \mathcal{I}_{i}
$$

Collect $N \times 1$ row vectors $\boldsymbol{\omega}_{i}^{\prime}=\left(\omega_{1}, \omega_{2}, \ldots, \omega_{N}\right)$, for $i=1,2, \ldots, N$, into $N \times N$ matrix $\boldsymbol{\Omega}$. In addition to (20)-21, we assume that the maximum absolute column sum matrix norm of $\boldsymbol{\Omega}$, denoted as $\|\boldsymbol{\Omega}\|_{1}$, is bounded in $N$, in order to rule out dominant economies $5^{5}$

Suppose that $\left\{a_{i t}\right\}$ follows a CWD process 10 with $\|\boldsymbol{\Sigma}\|=O(1)$. In this case,

$$
\kappa_{i t}=\beta(a_{i t}-\underbrace{\sum_{j \in \mathcal{I}_{i}} \omega_{i j} a_{j t}}_{O_{p}(1)}-\underbrace{\sum_{j \in \mathcal{I}_{i}^{c}} \omega_{i j} a_{i t}}_{O_{p}\left(N^{-\frac{1}{2}}\right)})+\eta_{i t}
$$

where $\mathcal{I}_{i}^{c} \equiv\{1,2, . ., N\} \backslash \mathcal{I}_{i}$ and

$$
\epsilon_{i t}=\beta\left(z_{i t}-x_{i t}\right)+\eta_{i t} \stackrel{q . m}{\rightarrow} \beta \sum_{j \in \mathcal{I}_{i}}\left(w_{i j}-\omega_{i j}\right) a_{j t}+\eta_{i t} .
$$

It can be seen that the residuals $\epsilon_{i t}$ are correlated with feasible regressors $x_{i t}$, other than in the special case where $w_{i j}-\omega_{i j}=O\left(N^{-1}\right)$ for any $j \in \mathcal{I}_{i}$ holds. Therefore neighborhood effects could lead to inconsistent estimates, if they are not appropriately captured by $\left\{w_{i j}\right\}$.

\footnotetext{
${ }^{5}$ The simple model developed in Appendix B where asset markets are complete and there is a single homogenous good does not feature any neighborhood effects.
} 


\subsection{Summary of findings and implication for the empirical analysis}

Summarizing the findings one can conclude that $\widehat{\beta}$ is consistent in all cases where $z_{i t}-x_{i t} \stackrel{q . m .}{\rightarrow} 0$ (uniformly in $i$ ). The inconsistency of $\widehat{\beta}$ can be caused by a set of different reasons, such as neighborhood effects, the presence of a dominant economy, or by a special scenario of strongly cross-sectionally dependent fundamentals. In the later two cases, the residual in the infeasible regression follows a factor structure. To be able to distinguish between these different scenarios would require both large $N$ and large $T$ panel, which is typically not possible. Given the likelihood that applying the AFV restriction could lead to inconsistent estimates, a test for the validity of this restriction in panel regressions appears therefore warranted.

\section{A test of the AFV restriction in panel regressions}

Let $T=1$, that is $\kappa_{i}$, for $i=1,2, \ldots, N$, is generated as

$$
\kappa_{i}=\beta z_{i}+\eta_{i}
$$

where we drop time subscripts, $z_{i}=a_{i}-\sum_{j=1}^{N} \omega_{i j} a_{j}$, (as before $\omega_{i j}$ are the unobserved aggregation weights and $\left.\omega_{i i}=0\right){ }^{6}$ For ease of exposition the analysis assumes that there is one regressor and $T=1$. However, to relax the assumption to the case $k>1$ regressors and $T>1$ time periods is a straightforward extension when both $T$ and $k$ are fixed. Extension of the test to large $N$, large $T$ dynamic heterogenous panels is not straightforward and we leave it for future research.

The following assumptions are postulated.

ASSUMPTION 1 (Innovations) Errors $\eta_{i}$ for $i=1,2, \ldots, N$ are identically and independently distributed with mean 0 , variance $\sigma^{2}<\infty$ and finite fourth moments uniformly bounded in $N$.

ASSUMPTION 2 (Regressors/productivity process)

(a) (Spatial model) Let

$$
\mathbf{a}=\mathbf{R} \varepsilon
$$

where $\varepsilon=\left(\varepsilon_{1}, \varepsilon_{2}, \ldots, \varepsilon_{N}\right)^{\prime}, \varepsilon_{i}$ for $i=1,2, \ldots, N$, are independently distributed with mean 0 and finite

\footnotetext{
${ }^{6}$ Aggregation weights $\omega_{i}$ are function of all parameters of the structural economic model, are model-dependent, and treated as unknown.
} 
fourth moments, and

$$
\|\mathbf{R}\|_{1}<K,\|\mathbf{R}\|_{\infty}<K
$$

where $\|\mathbf{R}\|_{1}$ and $\|\mathbf{R}\|_{\infty}$ are the maximum absolute column and row sum matrix norms of $\mathbf{R}$, respectively, and $K<\infty$ is a constant that does not depend on $N$.

(b) (Factor model)

$$
\mathbf{a}=\vartheta+\Gamma \mathbf{f}
$$

where $\boldsymbol{\vartheta}=\mathbf{R} \varepsilon$, matrix $\mathbf{R}$ and process $\varepsilon$ satisfy conditions in Assumption 2. , $\mathbf{f}$ is $n \times 1$ vector of unobserved common factors, $n<K, E(\mathbf{f})=\mathbf{0}, \operatorname{Var}(\mathbf{f})=\mathbf{I}_{n}$, the fourth order moments of $\mathbf{f}$ are bounded, and factor loadings are given by

$$
\boldsymbol{\Gamma}=\boldsymbol{\tau} \gamma^{\prime}+\mathbf{V}_{\gamma}
$$

in which $\boldsymbol{\tau}$ is $N \times 1$ vector of ones, $\|\gamma\|<K$ is non-stochastic $n \times 1$ vector, and the rows of $N \times n$ matrix $\mathbf{V}_{\gamma}$, denoted as $\mathbf{v}_{\gamma i}$, for $i=1,2, \ldots, N$, are independently and identically distributed with mean $E\left(\mathbf{v}_{\gamma i}\right)=\mathbf{0}$, bounded variance $\left\|E\left(\mathbf{v}_{\gamma i} \mathbf{v}_{\gamma i}^{\prime}\right)\right\|<K$ and bounded fourth moments.

Consider the following feasible cross section regression,

$$
\kappa_{i}=\widehat{\beta} x_{i}+\epsilon_{i t}
$$

where the feasible regressor:

$$
x_{i}=a_{i}-\mathbf{w}_{i}^{\prime} \mathbf{a}
$$

is constructed according to the weights $\mathbf{w}_{i}, \mathbf{a}=\left(a_{1}, a_{2}, \ldots, a_{N}\right)^{\prime}$, and $\widehat{\beta}$ is the feasible LS estimator defined in (7). The null hypothesis of interest is consistency of the feasible regression, that is:

$$
H_{0}: \operatorname{plim}_{N \rightarrow \infty} \widehat{\beta}=\beta
$$

The alternative hypothesis is $H_{1}: \operatorname{plim}_{N \rightarrow \infty} \widehat{\beta}_{1} \neq \beta$. Under the null we must have that $x_{i}-z_{i} \stackrel{q . m .}{\rightarrow} 0$. Given assumptions 1 2 , as shown in Section 2, the null hypothesis can be expressed as

$$
H_{0}^{*} \text { : elements of }\left(\boldsymbol{\omega}_{i}-\mathbf{w}_{i}\right) \text { are uniformly bounded by } K / N \text {, }
$$


where the constant $K$ does not depend on $N$. Note that $\left(\boldsymbol{\omega}_{i}-\mathbf{w}_{i}\right)$ is the difference between the true and the regression aggregation weights, and we shall refer to the vector $\left(\boldsymbol{\omega}_{i}-\mathbf{w}_{i}\right)$ as a vector of weights errors. $\widehat{\beta}$ is consistent if the weights errors are small and bounded by $K / N$.

ASSUMPTION 3 Consider an auxiliary set of weights $\mathbf{h}_{i}$. Let us choose for any $i \in \mathbb{N}$, a sequence of vectors $\mathbf{h}_{i}$ of growing dimension $\left(\right.$ as $N \rightarrow \infty$ ) where $\mathbf{h}_{i}=\left(h_{i 1}, h_{i 2}, \ldots, h_{i N}\right)^{\prime}$, for $i=1,2, \ldots, N$ satisfy the granularity conditions (8)-(9).

Let us then augment the feasible regression 29 by an additional variable

$$
\xi_{i}=\mathbf{h}_{i}^{\prime} \mathbf{a}
$$

The following auxiliary regression is then considered,

$$
\kappa_{i}=\widehat{\beta} x_{i}+\widehat{\delta} \xi_{i}+e_{i}
$$

The key contribution of the paper is to prove that, under the null that the parameters in the panel regression are estimated consistently, an F- test of the redundancy (as $N \rightarrow \infty$ ) of the auxiliary regressor $\xi_{i}$ converges to a $\chi^{2}$-distribution (under certain conditions).

Proposition 1 More formally, suppose $\kappa_{i}$ for $i=1,2, \ldots, N$ is given by equation (24), and Assumptions 1, part (a) or part (b) of Assumption 2, and Assumption 3 hold. Then under the null hypothesis $H_{0}$ defined in (31) (i.e. $\left(\boldsymbol{\omega}_{i}-\mathbf{w}_{i}\right)$ satisfies (32)) and as $N \rightarrow \infty$,

$$
F \stackrel{d}{\rightarrow} \chi^{2}(1)
$$

where

$$
F=\frac{R S S_{x}-R S S_{x \xi}}{R S S_{x \xi}}(N-1)
$$

$R S S_{x \xi}$ is the residual sum of squares from the cross section regression of $\kappa_{i}$ on $\left\{x_{i}, \xi_{i}\right\}$ and $R S S_{x}$ is the residual sum of squares from the cross section regression $\kappa_{i}$ on $x_{i}$.

A proof of Proposition 1 is given in Appendix A.

This result is not trivial, since $\xi_{i}$ is in general not redundant for finite $N$, and $\xi_{i}$ can be $O_{p}(1)$ as well as $O_{p}\left(N^{-1 / 2}\right)$, depending on the pattern of cross section dependence in the process $\mathbf{a}$. This test is robust to weak or strong forms of cross section dependence in $\mathbf{a}$. 
Remark 1 The granularity requirements in Assumption 3 is needed for the asymptotic distribution of our test. If these conditions do not hold, then the F-test for the redundancy of $\xi_{i}$ would not necessarily attain the standard $\chi^{2}$ distribution derived below (as $N \rightarrow \infty$ ). A trivial example of $\mathbf{h}_{i}$ that satisfies Assumption 3 is the vector of equal weights (i.e. $h_{i j}=1 /(N-1)$ for $i \neq j$ and $\left.h_{i i}=0\right)$.

As discussed earlier, under the null hypothesis $x_{i}$ converges to $z_{i}$ as $N \rightarrow \infty$, individual weights errors are small, and $\xi_{i}$ is (asymptotically) redundant. The null encompasses different scenarios discussed in the previous section, where $\widehat{\beta}$ is consistent. In all these scenarios, the contribution of $\xi_{i}$ into the overall fit of 34 diminishes in $N$ and the $F$ statistic is distributed as $\chi^{2}(1)$.

Evidence of the statistically significant contribution of $\xi_{i}$ to the overall fit of (34), on the other hand, signals that $x_{i}$ is not sufficiently close to $z_{i}$ and as a consequence a different set of weights could approximate better $z_{i}$. When $x_{i}$ does not converges to $z_{i}$, then $\eta_{i t}$ does not converge to $\epsilon_{i t}, \widehat{\beta}$ is no longer consistent and $\eta_{i t}$ can be strongly cross-sectionally dependent. The alternative hypothesis

of inconsistency of $\widehat{\beta}$ arises when the individual elements of $\left(\boldsymbol{\omega}_{i}-\mathbf{w}_{i}\right)$ are not diminishing in $N$, which could easily arise for instance in Cases 3 and 4 discussed in the previous section.

There are several typical candidates for $\mathbf{w}_{i}$ in empirical applications. Typically choices are weights based on trade shares, international portfolio holdings (if data is available) or GDP shares (as in the illustrative example in the Appendix B). A straightforward choice for the auxiliary granular weights $\mathbf{h}_{i}$ is to assume equal weights.

\section{Monte Carlo experiments}

\subsection{Data generating process}

In order to investigate the small sample properties of the test, we undertake some Monte Carlo experiments. We consider the data generating process given by $(3)$, where we set $\beta=1, \eta_{i t} \sim$ $\operatorname{IIDN}(0,1)$ for $i=1,2, \ldots, N$, and $t=1,2, \ldots, T$, and the variable $z_{i t}$ is generated according to (4). The productivity process is generated according to factor model (27) with $n=1$ unobserved common factor:

$$
a_{i t}=\vartheta_{i t}+\gamma_{i} f_{t}
$$


where the unobserved factor $f_{t}$ is allowed to be serially correlated,

$$
f_{t}=0.9 f_{t-1}+v_{f t}, v_{f t} \sim I I D N\left(0,1-0.9^{2}\right)
$$

and the process $\vartheta_{i t}$ is generated as a weakly dependent bilateral spatial AR(1) process,

$$
\vartheta_{i t}=\frac{a_{\varepsilon}}{2}\left(\vartheta_{i-1, t}+\vartheta_{i+1, t}\right)+\varepsilon_{i t},
$$

where $0<a_{\varepsilon}<1$, and $\varepsilon_{i t} \sim \operatorname{IIDN}\left(0, \sigma_{\varepsilon}^{2}\right)$. As established by Whittle (1954), the unilateral spatial $\operatorname{AR}(2)$ scheme

$$
\vartheta_{i t}=\psi_{\varepsilon 1} \vartheta_{i-1, t}+\psi_{\varepsilon 2} \vartheta_{i-2, t}+\varepsilon_{i t}
$$

with $\psi_{\varepsilon 1}=\alpha_{\varepsilon}+\beta_{\varepsilon}, \psi_{\varepsilon 2}=-\alpha_{\varepsilon} \beta_{\varepsilon}, \alpha_{\varepsilon}=\left(1-\sqrt{1-a_{\varepsilon}^{2}}\right) / a_{\varepsilon}$, and $\beta_{\varepsilon}^{-1}=\left(1+\sqrt{1-a_{\varepsilon}^{2}}\right) / a_{\varepsilon}$, generates the same autocorrelations as the bilateral spatial AR(1) scheme (38). The process $\vartheta_{i t}$ is generated using the unilateral scheme 39 with 50 burn-in data points $(i=-49, \ldots, 0)$ and the initialization $\vartheta_{-51, t}=\vartheta_{-50, t}=0$. We set $a_{\varepsilon}=0.6$, and choose $\sigma_{\varepsilon}^{2}$ such that $\operatorname{Var}\left(\vartheta_{i t}\right)=1$.

Two different options for factor loadings are considered:

(i) No common factor, so $\gamma_{i}=0$ for all $i$. This means the productivity process is weakly cross-sectionally dependent.

(ii) With a common factor, such that $\gamma_{i} \sim \operatorname{IIDN}(1,1)$, which means the productivity process is strongly cross-sectionally dependent.

We also consider two different options for the weights used to aggregate the foreign variables:

a.) World without neighborhood effects. The first option for weights corresponds to a world of many small economies with each economy having a limited impact on all other. Therefore, the unobserved true weights $\omega_{i j}$, for $i, j=1,2, \ldots, N$, are generated as

$$
\omega_{i j}=\frac{\varsigma_{i j}}{\sum_{j=1}^{N} \varsigma_{i j}}, \text { with } \varsigma_{i j} \sim \operatorname{IIDU}(0,1)
$$

This ensures that $\omega_{i j}=O_{p}\left(N^{-1}\right)$, and $\sum_{j=1}^{N} \omega_{i j}=1$.

Weights $w_{i j}$ in the feasible regressions (34) are different from the unobserved weights $\omega_{i j}$ and 
are generated in a similar way, i.e.

$$
w_{i j}=\frac{\tilde{\varsigma}_{i j}}{\sum_{j=1}^{N} \tilde{\varsigma}_{i j}}, \text { with } \tilde{\varsigma}_{i j} \sim \operatorname{IIDU}(0,1) .
$$

b.) World with a dominant economy. The second option for weights corresponds to Case 3 in Section 2, where the world consists of one dominant economy, taken to be country 1, and many small economies. In this case the true unobserved weights are generated as follows.

$$
\omega_{i 1}=\lambda_{i} \text {, and } \omega_{i j}=\left(1-\lambda_{i}\right) \frac{\varsigma_{i j}}{\sum_{j=2}^{N} \varsigma_{i j}},
$$

for $i=1,2, \ldots, N$, and $j=2,3, . ., N$, where $\lambda_{i} \sim \operatorname{IIDU}(-0.1,0.1)$, and as before $\varsigma_{i j} \sim \operatorname{IIDU}(0,1)$. This ensures that $\omega_{i 1}=O_{p}(1)$ for all $i$ and $\omega_{i j}=O_{p}\left(N^{-1}\right)$ for all $i \neq j$.

The weights used in the feasible regression, $w_{i j}$, are assumed to not capture well the influence of the dominant economy, but are generated in a similar way as $\omega_{i j}$ :

$$
w_{i 1}=\tilde{\lambda}_{i}, \text { and } w_{i j}=\left(1-\tilde{\lambda}_{i}\right) \frac{\tilde{\varsigma}_{i j}}{\sum_{j=2}^{N} \tilde{\varsigma}_{i j}},
$$

for $i, k=1,2, \ldots, N$, and $j=2,3, . ., N$, where $\tilde{\lambda}_{i} \sim \operatorname{IIDU}(0,0.4)$, and as before $\tilde{\varsigma}_{i j} \sim \operatorname{IIDU}(0,1)$.

As we are interested in the size of the test, we run experiments for $N=25,50,75,100,200$, and $T=1,2,5,10,20$. For each $N$, weights $\omega_{i j}$ are generated at the beginning of experiments and are kept fixed across replications. All remaining stochastic variables are generated for each replication. Altogether we run 2000 replication and we report rejection rates at 5\% nominal level for the AFV test (as specified in Proposition 1), where the feasible restricted regression is given by (5) and the unrestricted regression is 34 . We set $h_{i j}=(N-1)^{-1}$ for $i \neq j$ and $h_{i i}=0$.

In the case of a world without dominant economy (and without neighborhood effects), the null hypothesis of the validity of the AFV restriction does hold in our Monte Carlo design, irrespective of whether the unobserved common factor is present or not, and the rejection rate corresponds to the size of the test. In the case of a world with one dominant economy, the null hypothesis of the validity of the AFV restriction does not hold in our Monte Carlo set-up (again irrespective of whether a common factor is present or not), and the rejection rate would correspond to the power of the test. We also report bias $(\times 100)$ and root mean square error $($ RMSE) $(\times 100)$ of $\widehat{\beta}$ computed based on (5). 


\subsection{Monte Carlo Results}

The findings from the Monte Carlo analysis are summarized in Table 1 which consists of four parts.

The upper part presents results for the experiments without common factors, i.e. assuming weakly cross sectionally dependent productivity in a world without neighborhood effects. This corresponds to Case 1 in Section 2. In this case, $\widehat{\beta}$ should be biased, but consistent as $N \rightarrow \infty$ and AFV restriction is admissible. This is confirmed by our findings. We see that $\widehat{\beta}$ is biased downwards, but this bias diminishes as $N$ increases. This is true for all values of $T$. RMSE also diminishes with an increase in $N$, and we see also improvements along the time dimension $T$. However, due to the bias for finite $N$, RMSE cannot converge towards zero as $T$ is increased without bounds, keeping $N$ fixed.

In the second panel of Table 1, we report the results of an experiment in a world without neighborhood effects, but this time with productivity following a strongly cross-sectionally dependent process (i.e. an unobserved common factor). This corresponds to Case 2 in Section 2, The results are qualitatively similar to those without common factors. We see that the bias of $\widehat{\beta}$ diminishes with an increase in $N$ in the case of small open economies and the size for AFV test is again close to $5 \%$, although we see a slight deterioration when $T=20$, suggesting the test becomes slightly oversized when $T$ is not small compared to $N(6 \%-8 \%$ when $T=20)$.

Turning into the third panel of Table 1 we report the Monte Carlo experiment of a world in which there is one globally dominant economy, and a weakly cross-sectionally dependent productivity (i.e. no common factor) - this corresponds to Case 3 in Section 2. In this case the null hypothesis of the AFV test will not hold and we see from the table that the bias of $\widehat{\beta}$, although small, is non-negligible and does not diminish with an increase in $N$ or $T$. For the small bias of $\widehat{\beta}$ under this Monte Carlo set-up, we see that the power of the AFV restriction is admissible, with the rejection rates around 24\%-92\% for $N=75$. Furthermore, the power increases with an increase with $N$ and/or $T$.

The results with both strongly cross-sectionally dependent productivity (i.e. a common factor) and a globally dominant unit are reported in the bottom panel of Table 1. They are qualitatively similar to those without a common factor. We see that the bias of $\widehat{\beta}$ does not diminish with an increase in $N$ in the presence of a dominant unit. Indeed, the bias of $\widehat{\beta}$ in the presence of dominant unit is slightly lower compared to the same experiment without common factor, but the power of AFV test seems to be slightly higher, at least when $T=1$ (and for all values of $N$ ), or when $N=25$ (and regardless of $T$ ). 


\section{$5 \quad$ Application to the estimation of current account regressions}

There are several instances where the curse of dimensionality might apply. We propose here one example from the current account literature which has recently gained in popularity. The empirical literature on current accounts can be divided into two strands depending on the estimation strategy. One strand of literature estimates dynamic specification for current account, see for instance Bussière et al. (2006) :7 The other strand of literature (Rahman (2008), Chinn and Prasad (2003), International Monetary Fund (2006), Ca' Zorzi et al. (2009) and Ca' Zorzi et al. (2012)) estimates static panel regressions using temporarily aggregated data 8

In what follows, we take the latter approach along the lines of Ca' Zorzi et al. (2012). Let $\mathbf{x}_{i t}$ be $k \times 1$ dimensional vector of macroeconomic fundamentals for country $i$ in period $t$ and let $m$ be the size of the temporal aggregation window and define the following temporal aggregates,

$$
\bar{\kappa}_{i \ell}=\frac{1}{m} \sum_{t=m(\ell-1)+1}^{m \ell} \kappa_{i t},
$$

and

$$
\overline{\mathbf{x}}_{i \ell}=\frac{1}{m} \sum_{t=m(\ell-1)+1}^{m \ell} \mathbf{x}_{i t},
$$

for $\ell=1,2, \ldots, M_{T}$, where $M=[T / m]$ is the integer part of $T / m$. The following static model is then estimated,

$$
\bar{\kappa}_{i \ell}=\boldsymbol{\beta}^{\prime} \overline{\mathbf{x}}_{i \ell}+\epsilon_{i \ell}
$$

where $i=1,2, \ldots, N$, and $\ell=1,2, \ldots, M_{T}$.

Chinn and Prasad (2003), or International Monetary Fund (2006), among others, set $m=4$, but we shall consider various choices of $m$ to analyze the sensitivity of the results to this parameter.

An important step in the estimation is the choice of the determinants. We use a balanced panel of 76 countries taken from Ca' Zorzi et al. (2012) where the following $k=14$ regressors are considered as plausible determinants of the current account: net foreign assets (NFA), oil balance,

\footnotetext{
${ }^{7}$ The major drawback of this approach is that given the limited number of time-series observations typically no more than 25-30 annual observations, and given the number of macroeconomic fundamentals is quite large, often more than 10, then homogeneity of the short-run coefficients is typically imposed given the limited degrees of freedom. However that has the implication that the level elasticities, which constitute the main object of interest, would be biased when the short-run dynamics are in fact not homogenous across countries.

${ }^{8}$ The advantage of this approach is that it in fact can yield consistent estimates of the homogenous long-run elasticities, even when the short-run dynamics are heterogenous, Pesaran and Smith (1995).
} 
investment, economic growth, fiscal deficit, income per capita, population growth, a measure of civil liberties, openness, a measure of financial deepening, young and old age dependency ratios, relative income squared and a dummy to capture the role of the Asian crisis. All determinants, except for oil balance and net foreign assets variables, are constructed relative to foreign trading partners. Economic intuition and the detailed description of these variables is provided in Ca' Zorzi et al. (2012).

We do not know what are the 'true' weights in this model, as different model assumptions might point to different sets of weights. We consider three alternative choices of weights: trade based, GDP based and equal weights. Trade weights are the most common choice in open economy empirical models. GDP based weights (constructed as a share of individual economies on the world output) would be predicted by the theoretical model in Appendix B, which features complete markets. Finally, equal weights are a trivial example of weights, which are granular by construction. The trade weights are derived from bilateral trade flows between economies over the period 2004-2006 where the trade data is taken from IMF DOTS database while GDP weights are constructed using the IMF World Economic Outlook data.

\subsection{Empirical findings}

The results for the level elasticities estimates are shown in Table 2 with all 14 variables included in the panel regression. For each case $m=(1,4,12)$ we report the results applying the three sets of weights. The elasticities for most variables reveal a relatively limited sensitivity to the choice of weights but for a few variables, such as the old age dependency ratio, the difference appears to be more important. It is difficult to gauge the importance of results in Table 2, as small differences in the level elasticities estimates might potentially be reflected in large differences in terms of contribution to the fitted values. This might be the case if the aggregated foreign fundamentals change sizably depending on the choice of weights.

Current account regressions are important from a policy perspective because they are used to derive so-called current account benchmarks. These are thought to be helpful in the evaluation of global imbalances and exchange rate disequilibria, after estimating/calibrating the responsiveness of exports and trade to exchange rate movements (for a thorough discussion see Bussière et al. $(2010)$.

In our application, as it turns out, the average difference (in absolute value) of the derived 
current account benchmarks across the three different weighting schemes is about 1 percentage point of GDP. This difference might be not small in cases where the imbalance is not clear-cut. The sensitivity analysis suggests higher uncertainty if one wishes to translate the notion of external imbalance to a precise measure of exchange rate misalignment. A difference of 1 percent of GDP in the current account benchmark might translate to 7-17 percentage points difference in the assessment of exchange rate misalignments using a fundamental equilibrium exchange rate (FEER) framework for the G3 economies (USA, Euro Area and Japan) 9 Incidentally, it was precisely the sensitivity of the degree of estimated exchange rate misalignments in the FEER framework to the choice of aggregation weights that was the original motivation for this paper.

Given what we have just said above, we apply our test to our current account application to test the admissibility of the AFV restriction. We do this by augmenting the Trade weighted and GDP weighted regressions with a set of aggregated foreign regressors $\mathbf{h}_{i}$, which satisfy the granularity conditions. We take the easiest possible example of granular weights, namely equal weights.

Table 3 reports the AFV test results for the 3 different temporal aggregation, i.e. $m=(1,4,12)$. We find that the AFV restriction is strongly rejected in both the case of trade and GDP weights. Indeed, the rejections are rather strong, and are significant at the $1 \%$ critical level. This suggests that there might be an important bias coming from aggregation of foreign variables in the estimation of level elasticities in Table 2 .

\section{Conclusions}

It is common in both theoretical and empirical models to aggregate economies in the rest of the world into one 'representative foreign economy'. A key contribution of this paper has been to show, using an illustrative model, that the AFV restriction is admissible only in special circumstances, a point so far ignored in the open economy macro literature. This paper provides a first step to fill this gap by devising an aggregation of foreign variables (AFV) test that can be applied in a static panel regression where $T$ is treated as fixed and $N$ is treated as large. We have shown that this requires conducting an F-test to evaluate the redundancy of a set of weighted regressors added to static panel regression. With reference to the global imbalance literature, we have shown one example in which this test fails. The conclusion that we reach, both from a modelling and empirical perspective, is that the AFV restriction may well lead to inconsistent estimates.

\footnotetext{
${ }^{9}$ See the sensitivity analysis reported in Table 4 of Bussière et al. (2010).
} 
A way forward in similar applications is to test the AFV restriction formally. Should the test fail, one might have to explore alternative avenues for dealing with the curse of dimensionality. More research appears warranted on understanding the consequences of the 'representative foreign economy' assumption and when alternatives should be looked for. 


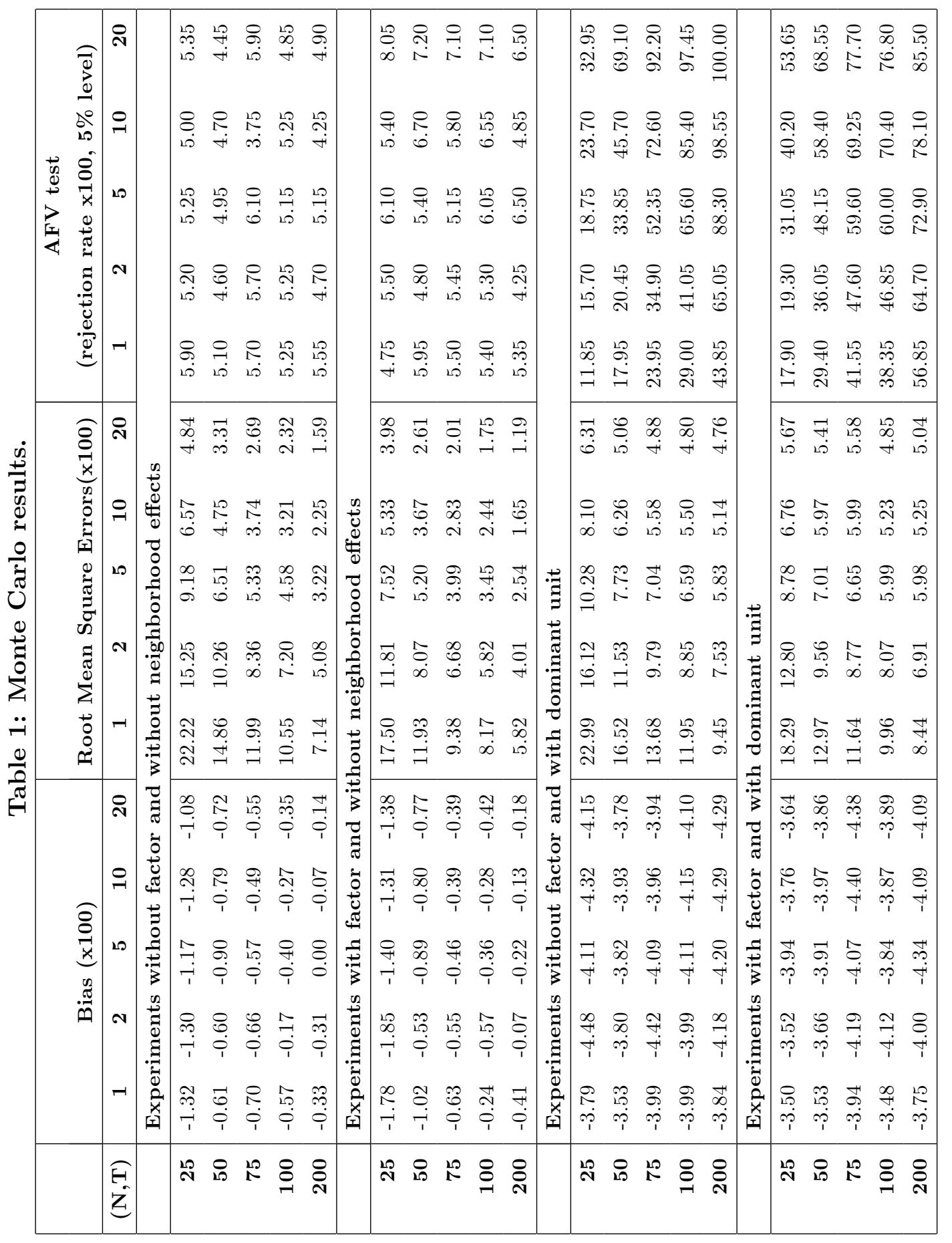

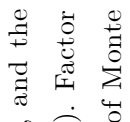

시잉

는

$\therefore$ चี

11 .

+ 范

ส

之

$\vdots$ 田

की

(1)

के

(

อ $\Rightarrow$

$\exists$

₹

교

Q 3

范

苛

焉

요

3 .

苛

-

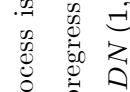

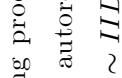

告

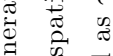

$\square_{\infty}^{\infty} \infty$

营

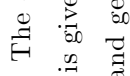

四

泀

की

田节

$\exists \therefore$

苞苛

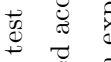

I

$\cong$ 乐

范落

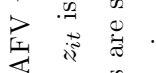


Table 2: Estimates of level elasticities

\begin{tabular}{|c|c|c|c|c|c|c|c|c|c|}
\hline \multirow{2}{*}{$\begin{array}{r}\text { Data shrinkage: } \\
\text { weights: } \\
\text { Variable }\end{array}$} & \multicolumn{3}{|c|}{ unfiltered $(m=1)$} & \multicolumn{3}{|c|}{ 4-year averages $(m=4)$} & \multicolumn{3}{|c|}{12 -year averages $(m=12)$} \\
\hline & Trade & GDP & Equal & Trade & GDP & Equal & Trade & GDP & Equal \\
\hline Initial NFA & $\begin{array}{r}\mathbf{0 . 0 3 5} \\
(7.2)\end{array}$ & $\begin{array}{r}\mathbf{0 . 0 3 5} \\
(7.6)\end{array}$ & $\begin{array}{r}\mathbf{0 . 0 3 4} \\
(7.3)\end{array}$ & $\begin{array}{r}\mathbf{0 . 0 3 4} \\
(5.7)\end{array}$ & $\begin{array}{r}\mathbf{0 . 0 3 5} \\
(6.2)\end{array}$ & $\begin{array}{r}\mathbf{0 . 0 3 4} \\
(5.9)\end{array}$ & $\begin{array}{r}\mathbf{0 . 0 3 0} \\
(6.4)\end{array}$ & $\begin{array}{r}\mathbf{0 . 0 3 2} \\
(7.2)\end{array}$ & $\begin{array}{r}\mathbf{0 . 0 3 0} \\
(6.6)\end{array}$ \\
\hline Oil balance & $\begin{array}{r}\mathbf{0 . 1 2 2} \\
(3.7)\end{array}$ & $\begin{array}{r}\mathbf{0 . 1 2 1} \\
(3.5)\end{array}$ & $\begin{array}{r}\mathbf{0 . 1 1 8} \\
(3.4)\end{array}$ & $\begin{array}{r}\mathbf{0 . 1 1 2} \\
(2.8)\end{array}$ & $\begin{array}{r}\mathbf{0 . 1 1 1} \\
(2.7)\end{array}$ & $\begin{array}{r}\mathbf{0 . 1 0 4} \\
(2.5)\end{array}$ & $\begin{array}{r}0.121 \\
(1.8)\end{array}$ & $\begin{array}{r}0.116 \\
(1.7)\end{array}$ & $\begin{array}{r}0.108 \\
(1.6)\end{array}$ \\
\hline Investment & $\begin{array}{r}-\mathbf{0 . 1 8 2} \\
(-5.0)\end{array}$ & $\begin{array}{r}-\mathbf{0 . 1 9 7} \\
(-5.1)\end{array}$ & $\begin{array}{r}-0.180 \\
(-5.0)\end{array}$ & $\begin{array}{r}-0.175 \\
(-3.7)\end{array}$ & $\begin{array}{r}-\mathbf{0 . 1 8 6} \\
(-4.1)\end{array}$ & $\begin{array}{r}-0.164 \\
(-3.7)\end{array}$ & $\begin{array}{r}-0.137 \\
(-1.7)\end{array}$ & $\begin{array}{r}-0.142 \\
(-1.7)\end{array}$ & $\begin{array}{r}-0.118 \\
(-1.4)\end{array}$ \\
\hline Ec. Growth & $\begin{array}{r}-0.036 \\
(-1.0)\end{array}$ & $\begin{array}{r}-0.052 \\
(-1.4)\end{array}$ & $\begin{array}{r}-0.037 \\
(-1.0)\end{array}$ & $\begin{array}{r}0.008 \\
(0.1)\end{array}$ & $\begin{array}{r}-0.036 \\
(-0.3)\end{array}$ & $\begin{array}{r}-0.038 \\
(-0.4)\end{array}$ & $\begin{array}{r}0.249 \\
(1.3)\end{array}$ & $\begin{array}{r}0.186 \\
(1.0)\end{array}$ & $\begin{array}{r}0.152 \\
(0.8)\end{array}$ \\
\hline Fiscal deficit & $\begin{array}{r}\mathbf{0 . 2 5 9} \\
(4.6)\end{array}$ & $\begin{array}{r}\mathbf{0 . 2 4 6} \\
(4.4)\end{array}$ & $\begin{array}{r}\mathbf{0 . 2 2 8} \\
(4.1)\end{array}$ & $\begin{array}{r}\mathbf{0 . 2 5 9} \\
(3.9)\end{array}$ & $\begin{array}{r}\mathbf{0 . 2 5 8} \\
(3.7)\end{array}$ & $\begin{array}{r}\mathbf{0 . 2 3 7} \\
(3.5)\end{array}$ & $\begin{array}{r}0.171 \\
(1.9)\end{array}$ & $\begin{array}{r}\mathbf{0 . 1 8 1} \\
(2.1)\end{array}$ & $\begin{array}{r}\mathbf{0 . 1 6 6} \\
(2.1)\end{array}$ \\
\hline Rel. income & $\begin{array}{r}-0.004 \\
(-0.7)\end{array}$ & $\begin{array}{r}-0.006 \\
(-0.9)\end{array}$ & $\begin{array}{r}0.000 \\
(0.0)\end{array}$ & $\begin{array}{r}0.001 \\
(0.2)\end{array}$ & $\begin{array}{r}-0.001 \\
(-0.2)\end{array}$ & $\begin{array}{r}0.004 \\
(0.8)\end{array}$ & $\begin{array}{r}0.012 \\
(1.7)\end{array}$ & $\begin{array}{r}0.010 \\
(1.3)\end{array}$ & $\begin{array}{r}\mathbf{0 . 0 1 2} \\
(2.1)\end{array}$ \\
\hline Pop. Growth & $\begin{array}{r}-\mathbf{0 . 4 2 3} \\
(-2.8)\end{array}$ & $\begin{array}{r}-\mathbf{0 . 4 6 0} \\
(-2.9)\end{array}$ & $\begin{array}{r}-\mathbf{0 . 3 8 7} \\
(-2.8)\end{array}$ & $\begin{array}{r}-0.695 \\
(-1.9)\end{array}$ & $\begin{array}{r}-0.714 \\
(-1.7)\end{array}$ & $\begin{array}{r}-0.541 \\
(-1.4)\end{array}$ & $\begin{array}{r}-1.046 \\
(-1.9)\end{array}$ & $\begin{array}{r}-1.038 \\
(-1.9)\end{array}$ & $\begin{array}{r}-0.874 \\
(-1.6)\end{array}$ \\
\hline Civil liberties & $\begin{array}{r}0.0033 \\
(1.6)\end{array}$ & $\begin{array}{r}0.0032 \\
(1.4)\end{array}$ & $\begin{array}{r}0.0042 \\
(1.9)\end{array}$ & $\begin{array}{r}0.0041 \\
(1.9)\end{array}$ & $\begin{array}{r}0.0038 \\
(1.6)\end{array}$ & $\begin{array}{r}\mathbf{0 . 0 0 5 0} \\
(2.1)\end{array}$ & $\begin{array}{r}\mathbf{0 . 0 0 6 8} \\
(3.0)\end{array}$ & $\begin{array}{r}\mathbf{0 . 0 0 6 2} \\
(2.6)\end{array}$ & $\begin{array}{r}\mathbf{0 . 0 0 7 4} \\
(3.0)\end{array}$ \\
\hline Openness & $\begin{array}{r}\mathbf{0 . 0 1 9} \\
(2.8)\end{array}$ & $\begin{array}{r}\mathbf{0 . 0 2 0} \\
(3.1)\end{array}$ & $\begin{array}{r}\mathbf{0 . 0 1 8} \\
(3.0)\end{array}$ & $\begin{array}{r}\mathbf{0 . 0 1 3} \\
(2.3)\end{array}$ & $\begin{array}{r}\mathbf{0 . 0 1 4} \\
(2.6)\end{array}$ & $\begin{array}{r}\mathbf{0 . 0 1 2} \\
(2.3)\end{array}$ & $\begin{array}{r}0.009 \\
(1.2)\end{array}$ & $\begin{array}{r}0.010 \\
(1.3)\end{array}$ & $\begin{array}{r}0.007 \\
(0.9)\end{array}$ \\
\hline Fin. deep. & $\begin{array}{r}0.000 \\
(0.0)\end{array}$ & $\begin{array}{r}0.001 \\
(0.5)\end{array}$ & $\begin{array}{r}0.001 \\
(0.6)\end{array}$ & $\begin{array}{c}0.001 \\
(0.6)\end{array}$ & $\begin{array}{r}0.002 \\
(1.1)\end{array}$ & $\begin{array}{r}0.002 \\
(1.2)\end{array}$ & $\begin{array}{r}0.003 \\
(0.9)\end{array}$ & $\begin{array}{r}0.003 \\
(1.3)\end{array}$ & $\begin{array}{r}0.003 \\
(1.3)\end{array}$ \\
\hline Dep. rat. old & $\begin{array}{c}-0.083 \\
(-1.2)\end{array}$ & $\begin{array}{r}-0.081 \\
(-1.2)\end{array}$ & $\begin{array}{r}-0.031 \\
(-0.5)\end{array}$ & $\begin{array}{r}-\mathbf{0 . 1 5 2} \\
(-2.1)\end{array}$ & $\begin{array}{r}-0.145 \\
(-2.0)\end{array}$ & $\begin{array}{r}-0.083 \\
(-1.1)\end{array}$ & $\begin{array}{r}-0.197 \\
(-2.4)\end{array}$ & $\begin{array}{r}-\mathbf{0 . 1 8 4} \\
(-2.3)\end{array}$ & $\begin{array}{r}-0.132 \\
(-1.6)\end{array}$ \\
\hline Dep. rat. young & $\begin{array}{r}-\mathbf{0 . 0 7 6} \\
(-3.6)\end{array}$ & $\begin{array}{r}-\mathbf{0 . 0 6 8} \\
(-3.3)\end{array}$ & $\begin{array}{r}-\mathbf{0 . 0 5 3} \\
(-2.5)\end{array}$ & $\begin{array}{r}-\mathbf{0 . 0 6 8} \\
(-3.0)\end{array}$ & $\begin{array}{r}-0.062 \\
(-2.6)\end{array}$ & $\begin{array}{r}-0.049 \\
(-1.9)\end{array}$ & $\begin{array}{r}-0.045 \\
(-1.5)\end{array}$ & $\begin{array}{r}-0.038 \\
(-1.2)\end{array}$ & $\begin{array}{r}-0.028 \\
(-0.8)\end{array}$ \\
\hline Rel. income sq. & $\begin{array}{r}-0.0012 \\
(-1.8)\end{array}$ & $\begin{array}{r}-\mathbf{0 . 0 0 1 3} \\
(-2.3)\end{array}$ & $\begin{array}{r}-0.0010 \\
(-1.7)\end{array}$ & $\begin{array}{r}-0.0006 \\
(-0.8)\end{array}$ & $\begin{array}{r}-0.0009 \\
(-1.5)\end{array}$ & $\begin{array}{r}-0.0005 \\
(-0.9)\end{array}$ & $\begin{array}{r}0.0009 \\
(1.0)\end{array}$ & $\begin{array}{r}0.0002 \\
(0.3)\end{array}$ & $\begin{array}{r}0.0005 \\
(0.7)\end{array}$ \\
\hline Asian dummy & $\begin{array}{r}\mathbf{0 . 0 4 8} \\
(3.6)\end{array}$ & $\begin{array}{r}\mathbf{0 . 0 4 0} \\
(4.5)\end{array}$ & $\begin{array}{r}\mathbf{0 . 0 4 1} \\
(4.4)\end{array}$ & $\begin{array}{r}\mathbf{0 . 0 4 6} \\
(3.3)\end{array}$ & $\begin{array}{r}\mathbf{0 . 0 4 0} \\
(4.3)\end{array}$ & $\begin{array}{r}\mathbf{0 . 0 4 2} \\
(4.1)\end{array}$ & $\begin{array}{r}\mathbf{0 . 0 4 8} \\
(2.3)\end{array}$ & $\begin{array}{r}\mathbf{0 . 0 3 9} \\
(2.7)\end{array}$ & $\begin{array}{r}\mathbf{0 . 0 4 2} \\
(2.7)\end{array}$ \\
\hline constant & $\begin{array}{r}0.002 \\
(0.6)\end{array}$ & $\begin{array}{r}-0.005 \\
(-1.2)\end{array}$ & $\begin{array}{r}-0.004 \\
(-1.3)\end{array}$ & $\begin{array}{r}0.002 \\
(0.6)\end{array}$ & $\begin{array}{r}-0.004 \\
(-1.0)\end{array}$ & $\begin{array}{r}-0.006 \\
(-1.8)\end{array}$ & $\begin{array}{r}0.002 \\
(0.5)\end{array}$ & $\begin{array}{r}-0.003 \\
(-1.0)\end{array}$ & $\begin{array}{r}-0.011 \\
(-3.9)\end{array}$ \\
\hline $\begin{array}{c}\text { Num. of countries } \\
\text { No. of obs. after } \\
\text { data shrinkage: }\end{array}$ & 1900 & 1900 & 76 & 76 & 76 & 76 & 76 & 76 & 76 \\
\hline
\end{tabular}

Notes: Statistical significance at $5 \%$ level is highlighted by bold fonts. t-ratios are in parentheses. 
Table 3: AFV test results

\begin{tabular}{lccc}
\hline \hline & $\mathbf{h}_{i}:$ & \multicolumn{3}{c}{ Equal weights } \\
\cline { 2 - 4 } Data shrinkage: & $m=1$ & $m=4$ & $m=12$ \\
\cline { 2 - 4 } $\mathbf{w}_{i}$ & & & \\
\hline Trade weights & 13.65 & 6.73 & 4.09 \\
GDP weights & 9.96 & 4.02 & 3.09 \\
\hline \hline
\end{tabular}

Notes: All rejections are significant at $1 \%$ level. $1 \%$ critical value for a random variable distributed as $\chi^{2}(r) / r$ with $r=12$ is 2.185 .

\section{References}

Bailey, N., G. Kapetanios, and M. H. Pesaran (2012). Exponents of cross-sectional dependence: Estimation and inference. CESifo Working Paper No. 3722.

Bussière, M., M. Fratzscher, and G. Muller (2006). Current account dynamics in OECD and new EU member states: an intertemporal approach. Journal of Economic Integration 21 (3), 593-618.

Bussière, M., M. C. Zorzi, A. Chudik, and A. Dieppe (2010). Methodological advances in the assessment of equilibrium exchange rates. ECB Working paper No. 1151.

Ca' Zorzi, M., A. Chudik, and A. Dieppe (2009). Current account benchmarks for central and eastern europe: A desperate search? ECB Working Paper series, No. 995.

Ca' Zorzi, M., A. Chudik, and A. Dieppe (2012). Thousands of models, one story: Current account imbalances in the global economy. forthcoming in Journal of International Money and Finance.

Chinn, M. and E. Prasad (2003). Medium-term determinants of current accounts in industrial and developing countries: an empirical exploration. Journal of International Economics 59, $47-76$.

Chudik, A. and M. Pesaran (2012). Econometric analysis of high dimensional VARs featuring a dominant unit. forthcoming in Econometric Reviews.

Chudik, A. and M. H. Pesaran (2011). Infinite dimensional VARs and factor models. Journal of Econometrics 163, 4-22.

Chudik, A., M. H. Pesaran, and E. Tosetti (2011). Weak and strong cross section dependence and estimation of large panels. Econometrics Journal 14, C45-C90.

Davidson, J. (1994). Stochastic Limit Theory. Oxford University Press.

Del Negro, M. and F. Schorfheide (2004). Priors from general equilibrium models for VARs. International Economic Review 45, 643-673.

Forni, M., M. Hallin, M. Lippi, and L. Reichlin (2000). The generalized dynamic factor model: Identification and estimation. Review of Economics and Statistic 82, 540-554.

Forni, M., M. Hallin, M. Lippi, and L. Reichlin (2004). The generalized dynamic factor model: Consistency and rates. Journal of Econometrics 119, 231-235. 
Forni, M. and M. Lippi (2001). The generalized factor model: Representation theory. Econometric Theory 17, 1113-1141.

Gali, J. and T. Monacelli (2005). Monetary policy and exchange rate volatility in a small open economy. Review of Economic Studies 72, 707-734.

Geweke, J. (1977). The dynamic factor analysis of economic time series. In D. Aigner and A. Goldberger (Eds.), Latent variables in socio-economic models. Amsterdam: North-Holland.

International Monetary Fund (2006). Methodology for CGER Exchange Rate Assessments. International Monetary Fund. available at: http://www.imf.org/external/np/pp/eng/2006/110806.pdf.

Pesaran, M. H. (2012). Testing weak cross-sectional dependence in large panels. mimeo, University of Cambridge, January 2012, available at: http://www.econ.cam.ac.uk/faculty/pesaran/wp12/Pesaran-WCD-Test-30-Jan-2012.pdf.

Pesaran, M. H. and R. Smith (1995). Estimating long-run relationships from dynamic heterogenous panels. Journal of Econometrics 68, 79-113.

Rahman, J. (2008). Current account developments in new member states of the European Union: Equilibrium, excess and EU-phoria. IMF Working Paper No. 92.

Sargent, T. J. and C. A. Sims (1977). Business cycle modeling without pretending to have too much a-priori economic theory. In C. Sims (Ed.), New methods in business cycle research. Minneapolis: Federal Reserve Bank of Minneapolis.

Whittle, P. (1954). On stationary processes on the plane. Biometrika 41, 434-449. 


\section{A Proofs}

Proof of Proposition 1. (a) First, suppose that Assumption 2 a holds. Since the least-squares fitted values are the same for any linear combination of regressors, which preserves the dimension of the space spanned by regressors, the F-test (35) is identical to the F-test constructed using the set of regressors $\left\{x_{i}, u_{i}\right\}$ in the unrestricted regression, where

$$
u_{i}=\sqrt{N} \xi_{i}=\sqrt{N} \mathbf{h}_{i}^{\prime} \mathbf{a}
$$

The F-test $F_{x \xi}$ can therefore be equivalently written as

$$
F_{x \xi}=\frac{\widehat{\beta}_{u}}{\sqrt{N}}\left[\widehat{v} \mathbf{s}_{2}^{\prime}\left(\frac{\mathbf{X}^{\prime} \mathbf{X}}{N}\right)^{-1} \mathbf{s}_{2}\right]^{-1} \frac{\widehat{\beta}_{u}}{\sqrt{N}},
$$

where $\widehat{\beta}_{u}$ denotes the OLS estimate of the coefficient corresponding to the regressor $u_{i}$ in the unrestricted cross-section regression of $\kappa_{i}$ on $\left\{x_{a i}, u_{i}\right\}, \mathbf{X}=\left(\mathbf{x}_{a}, \mathbf{u}\right), \mathbf{u}=\left(u_{1}, u_{2}, \ldots, u_{N}\right)^{\prime}, \mathbf{s}_{2}=(0,1)^{\prime}$ and $\widehat{v}$ is the usual estimator of variance of residuals in the unrestricted regression. In particular, $\widehat{\beta}_{u}=\mathbf{s}_{2}^{\prime}\left(\mathbf{X}^{\prime} \mathbf{X}\right)^{-1} \mathbf{X}^{\prime} \boldsymbol{\kappa}$, and $\widehat{v}=\widehat{\mathbf{e}}^{\prime} \widehat{\mathbf{e}} / N$, where $\widehat{\mathbf{e}}=\boldsymbol{\kappa}-\mathbf{X}\left(\mathbf{X}^{\prime} \mathbf{X}\right)^{-1} \mathbf{X}^{\prime} \boldsymbol{\kappa}$.

Note that $\kappa_{i}=\beta x_{i}+\eta_{i}+\beta\left(\boldsymbol{\omega}_{i}-\mathbf{w}_{i}\right)^{\prime} \mathbf{a}$. First we show that $N^{-\frac{1}{2}} \sum_{i=1}^{N} u_{i} \eta_{i}$ converges to a normal distribution. Let

$$
c_{N i}=\operatorname{Var}\left(u_{i}\right)=\operatorname{Var}\left(\sqrt{N} \mathbf{h}_{i}^{\prime} \mathbf{a}\right)=N \mathbf{h}_{i}^{\prime} \mathbf{\Sigma} \mathbf{h}_{i}, \text { for any } i \in\{1,2, \ldots, N\} \text {, and any } N \in \mathbb{N},
$$

where the subscript $N$ is used to emphasize the dependence on $N$. Assumption 2 and 3 imply $c_{N i}=O(1)$. It follows that

$$
\lim _{N \rightarrow \infty} \frac{1}{N^{2}} \sum_{i=1}^{N} c_{N i}^{2}=0
$$

and

$$
\underset{N \rightarrow \infty}{\limsup } \frac{1}{N} \sum_{i=1}^{N} c_{N i}<\infty
$$

Define

$$
Z_{N i}=\frac{u_{i} \eta_{i}}{\sigma \sqrt{\sum_{i=1}^{N} c_{N i}}}
$$

and let $\left\{\mathcal{F}_{N}\right\}$ denote an increasing sequence of $\sigma$-fields $\left(\mathcal{F}_{N-1} \subset \mathcal{F}_{N}\right)$ such that $Z_{N i}$ is measurable with respect to $\mathcal{F}_{N}$. Note that $\left\{Z_{N i}, \mathcal{F}_{N}\right\}$ and $\left\{Z_{N i}^{2}-E\left(Z_{N i}^{2}\right), \mathcal{F}_{N}\right\}$ are martingale difference arrays $\left(E\left(Z_{N i} \mid \mathcal{F}_{N-1}\right)=0\right.$ by Assumption 1 , and $E\left(Z_{N i}^{2}-E\left(Z_{N i}^{2}\right)\right)=0$ by definition.) Furthermore, since the fourth moments are finite, $\left[Z_{N i}^{2}-E\left(Z_{N i}^{2}\right)\right]$ is bounded in $L_{2}$ norm and therefore

$$
\left\{\left|Z_{N i}^{2}-E\left(Z_{N i}^{2}\right)\right|\right\} \text { is uniformly integrable. }
$$


Using a martingale weak law (Davidson (1994), Theorem 19.7), equations (A.4)-(A.7) imply

$$
\sum_{i=1}^{N}\left(Z_{N i}^{2}-E\left(Z_{N i}^{2}\right)\right) \stackrel{L_{1}}{\rightarrow} 0
$$

which establishes the following convergence

$$
\sum_{i=1}^{N} Z_{N i}^{2} \stackrel{p}{\rightarrow} 1
$$

where $\sum_{i=1}^{N} E\left(Z_{N i}^{2}\right)=1$. Moreover, we have

$$
\lim _{N \rightarrow \infty} \sum_{i=1}^{N} E\left(Z_{N i}\right)^{4}=0
$$

By Liapunov's theorem (see Davidson (1994), Theorem 23.11) condition (A.10) is sufficient for the following equation to hold,

$$
\max _{1 \leq i \leq N}\left|Z_{N i}\right| \stackrel{p}{\rightarrow} 0
$$

Finally, equations A.9 and A.11 imply, using a martingale central limit theorem (Davidson (1994), Theorem 24.3),

$$
\sum_{i=1}^{N} Z_{N i}=\frac{1}{\sigma \sqrt{\frac{1}{N} \sum_{i=1}^{N} c_{N i}}} \frac{1}{\sqrt{N}} \sum_{i=1}^{N} u_{i} \eta_{i} \stackrel{D}{\rightarrow} N(0,1)
$$

Note that $0<\frac{1}{N} \sum_{i=1}^{N} c_{N i}=O(1)$, but it is not required that $\lim _{N \rightarrow \infty} \frac{1}{N} \sum_{i=1}^{N} c_{N i}$ exists.

Furthermore, we have

$$
\begin{gathered}
\widehat{v} \stackrel{p}{\rightarrow} \sigma^{2}, \\
N^{-\frac{1}{2}} \sum_{i=1}^{N} u_{i}\left(\boldsymbol{\omega}_{i}-\mathbf{w}_{i}\right)^{\prime} \mathbf{a} \stackrel{p}{\rightarrow} 0,
\end{gathered}
$$

and

$$
\frac{\mathbf{X}^{\prime} \mathbf{X}}{N}-\mathbf{C}_{N} \stackrel{p}{\rightarrow} 0
$$

where

$$
\mathbf{C}_{N}=\left(\begin{array}{cc}
N^{-1} \sum_{i=1}^{N}\left[E\left(a_{i}^{2}\right)-2 \tilde{\mathbf{s}}_{i}^{\prime} \boldsymbol{\Sigma} \boldsymbol{\omega}_{i}+\boldsymbol{\omega}_{i}^{\prime} \boldsymbol{\Sigma} \boldsymbol{\omega}_{i}\right] & O\left(N^{-1 / 2}\right) \\
O\left(N^{-1 / 2}\right) & \frac{1}{N} \sum_{i=1}^{N} c_{N i}
\end{array}\right),
$$

and $\tilde{\mathbf{s}}_{i}^{\prime}$, for $i=1,2, \ldots, N$ is $N \times 1$ selection vector that selects the $i$-th element. Note that the diagonal elements of $\mathbf{C}_{N}$ are $O(1)$ and bounded away from zero, whereas the off-diagonal elements are $O\left(N^{-1 / 2}\right)$. Therefore, $\mathbf{C}_{N}$ is invertible for $N$ sufficiently large, and equation A.15) implies

$$
\mathbf{s}_{2}^{\prime}\left(\frac{\mathbf{X}^{\prime} \mathbf{X}}{N}\right)^{-1} \mathbf{s}_{2}-\left(\frac{1}{N} \sum_{i=1}^{N} c_{N i}\right)^{-1} \stackrel{p}{\rightarrow} 0
$$


Equations A.12, A.14 and A.13- A.17 establish $F_{x \xi} \stackrel{d}{\rightarrow} \chi^{2}(1)$. This completes the part (a) of this proof.

(b) Now suppose that Assumption 2, b holds instead of Assumption 2, a. It is useful to distinguish between the following two cases: $(i) \boldsymbol{\gamma}=\mathbf{0}$, and $(i i) \boldsymbol{\gamma} \neq \mathbf{0}$. In the former case, $E(\boldsymbol{\Gamma})=\mathbf{0}$ and we define $u_{i}$ in a similar way as in A.1,

$$
u_{i}=\sqrt{N} \mathbf{w}_{b i}^{\prime} \mathbf{a}=\sqrt{N} \mathbf{w}_{b i}^{\prime}(\boldsymbol{\vartheta}+\boldsymbol{\Gamma} \mathbf{f})=\sqrt{N} \mathbf{w}_{b i}^{\prime}\left(\boldsymbol{\vartheta}+\mathbf{V}_{\boldsymbol{\gamma}} \mathbf{f}\right)
$$

The process $\mathbf{w}_{b i}^{\prime} \boldsymbol{\vartheta}=\mathbf{w}_{b i}^{\prime} \mathbf{R} \boldsymbol{\varepsilon}$ is cross sectionally weakly dependent and, since the row and column matrix norms of $\mathbf{R}$ are bounded in $N$ (under Assumption 2. b), we have $\mathbf{w}_{b i}^{\prime} \boldsymbol{\vartheta}=O_{p}\left(N^{-1 / 2}\right)$, and $\sqrt{N} \mathbf{w}_{b i}^{\prime} \boldsymbol{\vartheta}=O_{p}(1)$. The process $\mathbf{w}_{b i}^{\prime} \mathbf{V}_{\boldsymbol{\gamma}}$ is also $O_{p}\left(N^{-1 / 2}\right)$ under Assumption 2 b. It follows that $u_{i}=O_{p}(1)$ and the result 35 can be established using similar arguments as in the part (a) of this proof. When $\boldsymbol{\gamma} \neq \mathbf{0}$, define $u_{i}$ in the following way:

$$
u_{i}=\mathbf{w}_{b i}^{\prime} \mathbf{a}=\mathbf{w}_{b i}^{\prime}\left(\boldsymbol{\vartheta}+\mathbf{V}_{\boldsymbol{\gamma}} \mathbf{f}\right)+\boldsymbol{\gamma}^{\prime} \mathbf{f}
$$

Since $\boldsymbol{\gamma}^{\prime} \mathbf{f}=O_{p}(1)$ and as established earlier $\mathbf{w}_{b i}^{\prime}\left(\boldsymbol{\vartheta}+\mathbf{V}_{\boldsymbol{\gamma}} \mathbf{f}\right)=O_{p}\left(N^{-1 / 2}\right), u_{i}$ continues to be $O_{p}(1)$. The derivation of (35) can now be established using similar arguments as in the part (a) of this proof. 


\section{B An illustrative current account model}

\section{B.1 Assumptions}

Suppose there are $N$ countries in the world economy, indexed by $i \in\{1,2, \ldots, N\}$. Each economy consists of population $L_{i} \in \mathbb{R}$ of homogenous consumers/workers. There is a single homogenous good in the world, whose price is without loss of generality normalized to 1 while all other variables are expressed in terms of this numeraire. Asset markets are complete. Each household faces the following optimization problem.

$$
U_{i t}=\max _{\left\{C_{i, t+k}, \mathcal{S}_{i \ell, t+k}\right\}_{k=0}^{\infty}} \mathrm{E}_{t} \sum_{k=0}^{\infty} b^{k} u\left(C_{i, t+k}\right)
$$

subject to the budget constraint, which can be written following Gali and Monacelli (2005) as

$$
C_{i t}+\mathrm{E}_{t}\left\{\mathfrak{M}_{i t, t+1} D_{i, t+1}\right\}=D_{i t}+W_{i t},
$$

where (due to symmetry) all households in economy $i$ consumes the same amount $C_{i t}, W_{i t}$ is common wage earned by a household in country $i, b$ is the discount factor and $D_{i, t+1}$ represents nominal payoff in period $t+1$ of the portfolio $\left\{\mathcal{S}_{i \ell t}\right\}_{\ell}$ held by a household in country $i$ at the end of period $t$ (including shares) . $\mathfrak{M}_{i t, t+1}$ is relevant stochastic discount factor,

$$
\mathfrak{M}_{i t, t+1}=b \frac{u^{\prime}\left(C_{i, t+1}\right)}{u^{\prime}\left(C_{i t}\right)} \frac{P_{i t}}{P_{i, t+1}} .
$$

Each firm produces the same homogenous good with labour being the only input. There is one representative firm in every country. The production function of the representative firm for simplicity is set equal to

$$
Y_{i t}=A_{i t} L_{i}
$$

where the productivity $A_{i t}$ is treated as stochastic and exogenous. For the simplicity of exposition, it is assumed that $a_{i t}=\ln \left(A_{i t}\right)$ is stationary.

\section{B.2 Market clearing}

There are two types of markets: goods and asset markets. Market clearing in goods markets implies that world consumption equals world output, in particular

$$
\sum_{i=1}^{N} C_{i t} L_{i}=\sum_{i=1}^{N} Y_{i t}
$$

Complete asset markets implies perfect risk sharing of households:

$$
\zeta_{i} C_{i t}=\zeta_{j} C_{j t}
$$

where constants $\left\{\zeta_{i}\right\}$ are determined up to a constant of proportionality and they depend in general on initial conditions regarding the net asset positions of households. 


\section{B.3 Equilibrium}

Substituting the implication of complete risk sharing of households given in equation B.6 into goods market clearing equation (B.5) establishes that individual consumption levels are proportional to the world aggregate output.

$$
C_{i t}=\frac{\zeta_{i}}{\zeta_{1}} C_{1 t}=\frac{\zeta_{i}}{\zeta_{1}} \frac{Y_{W t}}{\sum_{j=1}^{N} \frac{\zeta_{j}}{\zeta_{1}} L_{j}}
$$

where $Y_{W t}=\sum_{i=1}^{N} A_{i t} L_{i}$ is world aggregate output. The following equation for the current account easily follows:

$$
C A_{i t}=Y_{i t}-C_{i t} L_{i}=Y_{i t}-\frac{\zeta_{i}}{\zeta_{1}} \frac{Y_{W t}}{\sum_{j=1}^{N} \frac{\zeta_{j}}{\zeta_{1}} L_{j}} L_{i} .
$$

Let us denote the current account as a share of GDP as $\kappa_{i t}=C A_{i t} / Y_{i t}$. Dividing both sides of equation (B.8) by $Y_{i t}$, and using the approximation $1+X_{t}=\ln \left(X_{t}\right)$ and log-linear approximation to world output, yields (ignoring without loss of generality the constant)

$$
\kappa_{i t} \approx a_{i t}-\sum_{j=1}^{N} \omega_{i j} a_{j t}
$$

where $a_{i t}=\ln \left(A_{i t}\right)=\ln \left(\frac{Y_{i t}}{L_{i}}\right)$ is the logarithm of real GDP per capita (in PPP terms), weights $\left\{\omega_{i j}\right\}$ are given by

$$
\omega_{i j}=\left\{\begin{array}{cc}
\frac{\phi_{j}}{1-\phi_{i}} & \text { for } i \neq j \\
0 & \text { for } i=j
\end{array}\right.
$$

and $\phi_{j}$ is share of output in country $j$ on world aggregate output in a steady-state ${ }^{10}$

$$
\phi_{j}=\left[\frac{Y_{j t}}{Y_{W t}}\right]_{s s} .
$$

Remark 2 In this simple model, the correct aggregation weights $\left\{\omega_{i j}\right\}$ are related to GDP shares on world output. Different assumptions, however, could lead to a different set of weights - i.e. aggregation weights are model specific and thus unknown in practice. In empirical work, the trade weights seems to be the most commonly used when applying the AFV data shrinkage.

\footnotetext{
${ }^{10}$ If productivities were $I(1)$ then they would have to be cointegrated across countries (for any two country pairs) for steady-state shares $\phi_{j}$ to exist in this model.
} 